IMMEDIATE TYPE HYPERSENSITIVITY TO OVALBUMIN IN INFANTS AND CHILDREN - A MODEL FOR THE STUDY OF FOOD ALLERGY.

M.Thiemeier*, M.Kemeny**, C.Gens*, U.Wahn*

*Univ.Kinderklinik, Bochum, West Germany, and

**Guy's Hospital, London, U.K.

Ovalbumin has previously been demonstrated by us to be a major allergen of hen's egg (Folia Allergol.Immol.Clin. 30, 83 (1983)). In order to determine the value of allergological in vitro methods for the evaluation of food allergy, we studied 26 infants and children (3 months -12 years) with egg allergy and 10 bealthy controls. Serm concentrations of specific IgE and IgG antibodies to ovalbumin were detemined utilizing centrations of specific IgE and IgG antibodies to ovalbumin were determined utilizing were incubated with serial dilutions of ovalbumin for allergen induced histamine release. Histamine was assayed by the automated fluorometric technique. Titrated oral provocation tests with ovalbunin ( $1 \mathrm{mg}$ up to $1 \mathrm{~g}$ ) were performed in all patients. After oral provocation a typical immediate hypersensitivity reaction (urticaria, asthma, intestinal symptoms) was induced in 17 aut of 26 children. Neither the presence of specific serm IgE antibodies to ovalbumin nor a positive histamine release test predicted the clinical relevance of ovalbumin sensitivity.

arr data indicate that allergen induced histamine release fran leukocytes tends to give a better correlation with the results of provocation tests than specific serum IgE. However, all provocation tests should be performed to confirm a clinically relevant sensitivity to foods.
B. Sablayrolles; M. Piot ; G. Dutau ; P. Rochiccioli

Unité de Pneumologie et d'Immunoallergologie, Service de Pédiatrie CHU Rangueil Toulouse FRANCE

Twenty seven asthmatic children (A) aged $126 \pm 29$ months, and twenty seven ordinary children of the same age $(C)$ were studied. FeO2, FeCO2, minute ventilation ( $(E)$, breathing frequency (BF), heart rate (HR), blood pressure (BP), oxygen consumption (VO2), and respiratory exchange ratio (QR) were determinated during each stage of the progressive exercise and during the recovery. In the asthmatic group, there are significant decreases of $\mathrm{FeO2}, \mathrm{FeCO} 2$, vO2, load and $Q R$ at each stage and during the maximal exercise (Table I) The cardiac and respiratory recovery at $10 \mathrm{~min}$ were slower in $\mathrm{A}$ than $C: B F=120 \pm 11$ vs $104 \pm 3(p<0,01)$ and $D V 02=0,10 \pm 0,11$ vs $0,01+0,15 \mathrm{ml} / \mathrm{min}(\mathrm{p}<0,05)$

\begin{tabular}{|l|c|c|c|c|c|c|c|c|}
\hline & (wate $)$ & FeO2 & FeC02 & VE & BF & BP & VO2 & QR \\
\hline$A$ & $144 \pm 28$ & $3,3 \pm 0,3$ & $3,4 \pm 0,4$ & $46 \pm 18$ & $50 \pm 10$ & $15 \pm 2$ & $44 \pm 10$ & $1,1 \pm 0,1$ \\
$e$ & $173 \pm 28$ & $3,6 \pm 0,4$ & $4,1 \pm 0,5$ & $52 \pm 17$ & $49 \pm 11$ & $16 \pm 2$ & $53 \pm 9$ & $1,2 \pm 0,1$ \\
1 & 1 & 0,1 & NS & NS & NS & 1 & NS \\
\hline
\end{tabular}

Ventilation-perfusion maldistribution and obstruction during the exercise could explain the little limitation at the exercise in this group of asthmatic children.

\section{SURVEY OF HAY-FEVER IN ISRAELI CHILDREN.}

C. Geller-Bernstein and S. Levin. Pediatric Dept. A and Allergy Unit, Kaplan Hospital, Rehovot.

Central and Southern Israel have a desert climate ( 8 dry months/ year) with Mediterranean influences along the sea-shore and very rich grass vegetation (all planted and artifically irrigated). Children. especially those in rural settlements (Kibbutzim and Moshavim), spend much of their day-time from the early weeks of their lives on the much of their day-time from the early weeks of their lives on the cal pattern of hay-fever (H.F) we examined $86 \mathrm{children}$ presenting with typical H.F. for: age of onset and severity of symptoms, as well as IgE levels and skin tests to 20 allergens. Out of 46 children living in rural areas, H.F. symptoms in 36 began between $2-4$ years of age, 9 between $5-7$, and $i$ at age 10yrs. 24 cases had positive skin tests to more than 3 pollen extracts, and 21 to less than 3 . Out of the 40 more than 3 pollen extracts, and 21 to less than 3 . Out of the 40

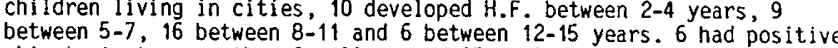
skin tests to more than 3 pollens and 35 to less than 3 . Severity of symptoms and IgE levels did not differ between rural and city children. Conclusions: atopic children living in rural areas with desert climate and irrigated vegetation, develop more sensitivities to grass pollens $(P<0.005)$ and earlier H.F. symptoms $(P<0.005)$ than city children in the same climate. All our children (rural and city) develop H.F. at earlier ages than reported in the literature.
250 SCG EFFECT ON MACROMOLECULAR ABSORPTION OF FOOD ANTIGENS IN ATOPIC DERMATITIS (AD).

G. Cavagni, R. Paganelli *,E. Rigoli. (Introduced byLBusinco). Dept. Paed.University of Parma; ${ }^{*}$ Dept. Allerg. Cl. Immunol. University of Rome - Italy.

In children with $\mathrm{AD}$ an abnormal absorption of macromolecules (mac) through the gut was observed. We challenged 6 children ( 11 mths. to 11 yrs. of age) affected by $A D$ with in vivo and in vitro evidence of hypersensitivity to ovoalbumin $(O A)$ and 4 to cow's milk ( $\propto$-lactalbumin AL) . The children were challenged with the specific allergenic food, the challenge was repeated with the pretreatment of oral SCG $(40 \mathrm{mg} / \mathrm{kg})$. The detection of mac. $(\mathrm{OA}, \mathrm{AL})$ in circulation was performed in solid phase (Paganelli et al.).

Results:

1) All the patients had skin and gut symptoms on the 1st occasion. Pretreatment with SCG prevented the occorrence of immediate symptoms;

2) Circulating $\mathrm{Ag}$ detected in sera after specific food challenge:

\begin{tabular}{lcccl} 
challenge & $\mathrm{Ag}$ & n. Cases & no SCG & yes SCG \\
\hline egg (white) & OA & 6 & $8,3 \mu \mathrm{g} / \mathrm{l}$ & $4,1 \mu \mathrm{g} / \mathrm{l}$ \\
cow's milk & $\mathrm{AL}$ & 4 & $2,1 \mu \mathrm{dl}$ & $1,5 \mu \mathrm{g} / \mathrm{dl}$
\end{tabular}

SCG was able to reduce the absorption of mac.

This finding may indicate that effectiveness of SCG in preventing the symptoms is due to both reduced and delayed absorption.

\section{CORD-BLOOD IgE DETERMINATION BY ENZYME-IMMUNNO-ASSAY.} CORRELATION BETWEEN ABOVE NORMAL IgE VALUES AND LYMPHOCYTE-POPULATTONS.

CP Bauer, R Franz,BH Belohradsky. Dept.Paed.Techn.Univ.Rechts d.Isar, Munich and Dept. Ped. Dnjw Munich. FRG.

Cord-blood IgE was determined prospectively in 300 neonates by an enzyme-immuno-assay (Phadezym-Prist) (EIA) and a radio-immuno-assay (Phadebas-Prist)(RIA). In order to obtain sufficient sensitivity for the EIA, determinations were performed with undiluted sera, and calibration curves were newly established. The lowest value determined was at $0.125 \mathrm{kU} / \mathrm{l}$. A comparison of EIA and RIA revealed no significant differences for single determinations. The geometric mean was $0.246 \mathrm{kU} / 1 ; 2-\mathrm{SD}$ was $1.0 \mathrm{kU} / \mathrm{l}$ for both test systems.

$10 \%$ of the cord-blood values were above $1.0 \mathrm{kU} / 1$ ( $n=29$ neonates) $10 \%$ of the cord-blood values were above $1.0 \mathrm{kU} / 1$ ( $\mathrm{n}=29$ neonates);
a follow-up of these 29 infants 18 months after birth detected 19 with symptoms of atopy (atopic dermatitis=14; allergic asthma $=4$; urticaria with cow-milk-allergy=1).

The presented data would suggest that EIA and RIA are comparably sensitive and valuable methods for the determination of IgE-levels in cord-blood. An early risk factor for the development of atopic diseases in infancy can thus be detected.

In addition, 200 of the 300 cord-blood sera were studied for $\mathrm{T}$ - and $\mathrm{B}$-lymphocyte distribution by the use of monoclonal antisera in a routine immunofluorescence assay. A correlation between above normal values of $\operatorname{IgE}(>1.0 \mathrm{kU} / \mathrm{l})$ and the distinct lymphocyte populations, including $\mathrm{T}$-helper- and $\mathrm{T}$-suppressor-cells, could not be demonstrated.

\section{IMMUNODEFICIENCY IN CHILDREN WITH RECURRENT \\ RESPIRATORY INFECTIONS. KS Sloper, JM Parkin,
JC Bridges, AJ Pinching, JO Warner}

Dept. Paed. Brompton Hospital, Iondon and Dept. Immunology, St.Mary's Hosp. Med. School, Praed St., London.

54 children, $M: F=1: 1$, with recurrent respiratory infections and 54 children, $M: F=1: 1$, with recurrent respiratory infections and including serum immunoglobulins, nitroblue tetrazolium test, neutrophil and monocyte candida phagocytosis and killing, random locomotion and chemotaxis, and Saccharomyces opsonisation. 33 (618) patients had at least one immune abnormality, including IgA deficiency $4 \%$, opsonisation defect $19 \%$, neutrophil or monocyte killing: serum dependent $30 \%$, cell dependent 15\%, and locomotor killing: serum dependent $30 \%$, cell dependent 158, and locomotor
defect 26\%. Some patients had more than one defect. Two patients defect 26\%. Some patients had more than one defect. Two patients transiently, and both had asthma but no immunodeficiency. There was no difference in the incidence of asthma in patients with and without immunodeficiency $(17$ of $33 \mathrm{v} 14$ of 21$)$. Bacteria were isolated from sputum in 638 (34 of 54), the commonest organisn being Haemophilus influenzae found in 528 with immunodeficiency and $38 \%$ without, whereas no difference was found for Pseudomonas (19\%), Group A Streptococcus $(208)$ and Strep. pneumoniae (278).

This demonstrates that significant immunological abnormalities are common in patients with recurrent chest infections, with or without asthma, and are much comoner than ciliary defects in cystic fibrosis or Kartagener's syndrome. Isolated opsonisation defects are uncommon and may only be clinically relevant if associated witt other serum dependent defects of phagocytosis and/or killing. 